\title{
SOCIAL ENTREPRENEURSHIP IN BULGARIA
}

\author{
Venelin Terziev $^{1 \star}$, Dimitar Kanev ${ }^{2}$, Veselin Madanski ${ }^{3}$ \\ ${ }^{1}$ Professor, Ph.D., D.Sc. (National Security), D.Sc. (Ec.), University of Rousse, Rousse, Bulgaria; \\ National Military University, Veliko Tarnovo, Bulgaria; University of Telecommunications and Post, \\ Sofia, Bulgaria, Russian Academy of Natural History, Moscow, Russia, e-mail: terziev@skmat.com \\ ${ }^{2}$ Naval Academy, Varna, Bulgaria, e-mail: kanev@dkanev.com \\ ${ }^{3}$ National Military University, Veliko Tarnovo, Bulgaria, e-mail: madansky@yahoo.com \\ ${ }^{*}$ Corresponding author
}

\begin{abstract}
Innovative ideas in public policy are crucial to support the values of an active-oriented problem solving social system. These views underlie the ongoing social reforms in various countries and focus on the development of social entrepreneurship and the role of social entrepreneurs. An understanding is underlined that namely social entrepreneurs have the capability through localization of usable resources - human capital, buildings and equipment, to find flexible approaches to satisfy unmet social needs. The study presented in the article provides important implications on the state of the social entrepreneurship in Bulgaria and ways of its encouragement putting a special accent on the needed support and building capacity.
\end{abstract}

Keywords: social economy, social enterprise, social entrepreneurship

\section{INTRODUCTION}

The problem of social entrepreneurship is entirely determined by economic and cultural contexts in the country (Terziev, Bencheva, Arabska, Stoeva, 2016 pp. 203-208). It can be concluded that the concept of social entrepreneurship is a relatively young both as theory and practice. Undoubtedly there is a misunderstanding of this project, not only by society but also by the authorities of the tax and legislative regulation. In the public perception there is an underlying understanding that social entrepreneurship is a type of social labour readjustment of unprotected groups in commercial enterprises. From the legislative point of view itself law for non-profit organizations, albeit allowing the conduct of business by NGOs, is not sufficient to stimulate similar initiatives. On the one hand, the lack of explicit mention of the social enterprise category leads to a situation in which existing social enterprises are often not perceived in such a quality. On the other hand, the experience of developed countries shows that the majority of social entrepreneurs start a business with a donation of social capital in the form of networks of relationships and acquaintances linked 
by common values and interests. Fundraising through charity, volunteer work and corporate responsibility entails expansion of capital and thus leads to generation of new products and services (Rusanova, 2011, pp. 28-32).

Repeatedly in various acts the Economic and Social Council of the country has emphasized that social entrepreneurship plays an important role for social cohesion and the creation of growth and jobs. Typological features of this type of entrepreneurship in Bulgaria do not differ greatly from those of similar enterprises in the rest of Europe (Kumanova, Shabani, 2013,):

- Clear social impact - in the main activity on a balance between the pursuit of profit and direct support to the social status of certain groups.

- Clearly defined target group - mainly persons from socially vulnerable groups - those who need help to equalize their life or social status to that of other members of society.

- Specific business purpose - is aimed at improving living standards, employment, provision of services and other forms of direct support in order to overcome social exclusion of the target group.

In the modern European context, the social economy is an established and integral part of social protection and social safety nets, which produces and successfully combines economic profitability and social solidarity. The social economy is a carrier of the democratic values that put people first, creating jobs and promoting active citizenship. Actually existing entities with social economic and humanitarian activities in the country say more strongly the need for legal and institutional differentiation in the real economy to be able to fulfill their potential and interact on an equal basis for achieving synergistic social effect among themselves and in cooperation with state and corporate economy.

Challenges facing the social enterprises in Bulgaria are identified (Todorova, 2014):

1. Lack of legal framework relating to the definition of social enterprises in order to properly guide policies in Bulgaria there is still no legal definition of social enterprise, but has a set of characteristics (in National Concept for Social Economy) which are the starting point for identifying social enterprise.

2. The majority of social enterprises in Bulgaria are aimed at providing different types of services (passive) while social entrepreneurship should develop towards active engagement of target groups in the process.

3. Problems encountered during the operation of social enterprises: facilities, administration, personnel, equipment;

4. Lack of sufficient incentives related to the supply of products of social enterprises in the market;

5. Interaction with other companies, organizations, administrations;

6. The need for training and motivation of people working in social enterprises and those who wish to take up a job there.

Social entrepreneurship is one of the most innovative ways to achieve a better quality of life, independence and inclusion in society of persons from vulnerable groups. Need to be taken key legislative changes in order set in strategic and political national documents measures to become real mechanisms to support social entrepreneurship in Bulgaria, as well as the successful development of social enterprises, requires the creation of sustainable partnerships between business, NGOs and the public sector - partnerships in which each of these actors recognizes its role to achieve socially important objectives and is willing to invest resources in that (Aleksieva, Shabani, Panov, 2013).

\section{MATERIAL AND METHODS}

The article presents the results of a study conducted under the project SESBA - Social enterprise skills for business advisors, aimed at formulating the basic conclusions about current needs and ways to promote social entrepreneurship. The assessments are made and presented below according to the Likert scale from 1 to 5 .

\section{RESULTS AND DISCUSSION}

The experience referred in the following areas: work in cooperatives, incl. agricultural; work in the social sphere; work with children, individuals and families at risk; work with people from nursing homes; work as a volunteer; work as a teacher, incl. training of children with special educational needs; work as an accountant, incl. social enterprises; experience abroad (Canada), incl. observations on the development of social entrepreneurship; human resource management in the enterprise; working in NGOs; work in municipal 
structures.

Respondents indicate strongly that in the functioning of organizations the striving must be after responsibility and profit, followed by social values and professional relationships, communication with the external environment and career development. Placing responsibility before profit is indicative of the consensus on the need to change to new business models driven by something that is more by profit, particularly linking the activities of organizations with significant social goals.

Definition of social entrepreneurship is based on reinvestment of profits for social purposes are best accepted. At the highlights of the social mission of market-oriented activities and social transformation respondents are more neutral, ie understanding is leading to denial of maximizing profit for shareholders and owners to the benefit of society. According to the respondents a unified understanding is needed on the essence of social entrepreneurship, social enterprises, social economy, etc. The role is highlighted of government policies and the efforts of local authorities, as well as studies on "foreign experience". Among the benefits of the development of social entrepreneurship are: an opportunity to develop socially engaged business; a good opportunity for helping people in need; satisfaction with work.

Respondents generally show fluctuations on whether society is ready to accept and support social entrepreneurship, most are rather neutral (36\%) and agree (34\%). Dissenters are $8 \%$ and fully agree - only $23 \%$ of respondents. This shows the need for a more thorough study of the causes and a need to seek improvements once the answers to the above questions highlight the advantages and benefits of social entrepreneurship that respondents are well aware of and accept. Respondents indicated that the concept of social entrepreneurship is unknown to the majority of society, and information on social entrepreneurship among business organizations in Bulgaria is insufficient and needs to work systematically and consistently to raise awareness and motivation for the development of social enterprises.

General opinion of the respondents is that social entrepreneurship should be promoted by European programs, strategies for regional and local development and the state policy, and to ensure national funding. The question of how it is appropriate to rely on funding provided by the European funds and programs, the national budget and the degree of state intervention, is one of the main discussed by respondents in the following open questions about opinions and recommendations. This is the key moment in the development of social enterprises - reliance on temporary financing or separately and sequentially development towards sustainability. Additions made by some, albeit inaccurate and incomplete, point to the role of civil society, public

The need to raise public awareness of social entrepreneurship has been adopted by respondents in respect of the preliminary versions of the awareness campaigns organized by public authorities or non-governmental organizations; brochures, books and other materials; TV spots, etc.; informal training. The additional options given by some respondents stress on the importance of social networks and sharing good examples, as it is stated a focus on the most early school education and the need for individual approaches again.

Consideration of the most significant barriers to the development of social entrepreneurship focuses on funding opportunities and the lack of government policies pursued by the lack of knowledge and lack of legal structure. Local business environment, credit access, public perceptions, market access and the absence of consultants also solidified their place among the major problems.

Needs and opportunities to support social enterprises the survey emphasizes on training, funding, legal framework, consulting and entrepreneurial orientation. Good results are also acquired in terms of promoting access to public procurement and inspiration. Among the additions made possible options are those associated with public interest and support, public awareness and change of thinking.

Among the additions are highlighted the role of counselors in training of staff in social enterprises, establishment of contacts and lasting relationships with social partners, opportunities to develop social activities and communications. A very interesting opinion expressed by the representative of the municipal structure that consulting services should be periodic rather than constant, which draws attention to the need to build capacity and achieve self-sufficiency in various aspects - economic and governance.

Among respondents there is a consensus that specialized training is needed in the field of social entrepreneurship. Vocational training is proving the most appropriate according to the average estimates given by respondents, followed by formal and informal learning. In terms of higher and secondary education fluctuations are larger. The additions are oriented towards the need of training on the very essence of social entrepreneurship, social services, soft skills, ICT and communication skills, psychological trainings.

On the type of institutions that should provide specialized training in the field of social entrepreneurship the focus in assessing by the respondents falls on organizations offering specialized consulting services and 
vocational training centers. Higher schools, vocational schools and colleges and secondary schools receive less support, which is in line with the answers to the previous question about the type of education / training. Specific addition to which there are serious grounds are NGOs, primary schools (as already noted in some of the previous issues) and training within the organizations themselves.

Estimates of the form of training are again oriented towards training in the workplace, as well as blended learning, e-learning, which replace traditional full-time and part-time, providing high availability and flexibility. The additional remarks referred to the compulsory subjects in social entrepreneurship in formal education, but also to self-learning, stressing once again the importance of activities to increase motivation for developing social entrepreneurship and personal motivation for training and development.

The answers to questions about the skills required of social entrepreneurs, showed very good and good grades.

The pursuit of social initiatives and awareness of personal responsibility among respondents is commendable, but the responses highlight the need for raising awareness, acquiring knowledge, skills and competences for the development of social entrepreneurship. Moreover, in this regard the need for consulting services is undeniable, and the role of consultants and consultancy organizations to promote social entrepreneurship.

\section{CONCLUSION}

The study presented provides important implications on the state of the social entrepreneurship. The main recommendations to promote social entrepreneurship include:

Conceptual base and value system: a unified understanding is needed on the essence of social entrepreneurship, social enterprises, social economy, etc.;

Regulatory framework and institutions: government policies supporting initiatives for social entrepreneurship needed; they must include the state (municipal) and private structures;

Support: state and local government can only facilitate the process, but the initiative must come from the private sector;

Models: the better option is each company to develop social activities, albeit in a smaller scope, rather than relying on fewer but larger social enterprises.

Training: establishment of a value system should start from an early age. To provide training in specific programs, events, etc., in which participants can join - receive information, experiences and a result in their development.

Cooperation: state, local governments and private producers to unite and create links among themselves on supporting the development of social entrepreneurship; social entrepreneurs to unite in associations by exchanging experiences and ideas.

\section{ACKNOWLEDGEMENTS}

This paper is prepared under the Erasmus+ Strategic Partnerships Project entitled SESBA: Social Enterprise Skills for Business Advisers (2015-1-EL01-KA202-014097), funded with the support from the European Commission. The European Commission support for the production of this publication does not constitute an endorsement of the contents which reflects the views only of the authors, and the Commission cannot be held responsible for any use which may be made of the information contained therein.

\section{REFERENCES LIST}

Rusanova. L. (2011). The concept of social entrepreneurship and Bulgarian experience. Scientific works of the University of Ruse - Vol. 50, Series 5.1, $2832(\mathrm{Bg})$.

Kumanova, M., Shabani, N. (2013) Analysis of social entrepreneurship in Bulgaria. Project "Initiative for innovations in social economy".

Aleksieva, P., Shabani, N., Panov, L. (2013) Handbook "New opportunities for social enterprises. The Italian experience in Bulgarian conditions". Project "Initiative for innovations in social economy".

Todorova, T. (2014). Social enterprises in Bulgaria - an innovative model of employment and social 
inclusion. Project "Creation of a national data base of social enterprises in Bulgaria".

Terziev, V., Bencheva, N. Arabska, E., Stoeva, T., Tepavicharova, M., Nichev, N. (2016). Implications on social entrepreneurship development in Bulgaria. Knowledge International Journal Scientific Papers Vol. 13.1, 203-208. 